\title{
EFFECT OF EDUCATIONAL COURSES AND GENDER UPON MENTAL HEALTH OF POST GRADUATE STUDENTS IN KOLKATA
}

KEY WORDS: Mental Health, Educational Courses, Gender, Subjective Well-being

\section{Sujata Saha*}

\section{2/ D, B.K Paul Lane, Dum Dum Road (Near RBI staff Quater) Kolkata -700030 *Corresponding Author}

Mental health or subjective well-being makes up an integral part of an individual's capacity to lead a fulfilling life, including the ability to form and maintain relationships , to study, work or pursue leisure interests and to make day- today decisions about educational, employment, housing or other choices . Disturbances to an individual's mental wellbeing can adversely compromise these capacities and choices, leading not only to diminish functioning at the individual level but also broader welfare losses at the household and societal level. Social and psychological scientists have been studying something positive in the domain of subjective well-being - individual's evaluations and judgement of their own lives for about 50 years.(Keyes ,2006b). When factor analysed, studies showed that the manifold scales measuring subjective well-being present the latent structure of hedonic well-being (i.e, positive emotions towards one's life) or eudemonic well being (i.e positive psychological and social functioning in life; Keyes, Shmotkin \& Ryff ,2002;McGregor \&Little ,1998;Ryan \& Deci ,2001).Against this backdrop the paper examines that educational courses as well as gender showed some impact upon mental health -the subjective well-being that constructed difference in the roles and responsibilities of male and female college students from post-graduation in Kolkata. Three hypotheses were formed. The findings spoke clearly about $\mathrm{i}$ a) Mental health varies according to the different educational course of the students.ib) Mental health varies according to the gender of the students ic) There is an impact of interaction between different educational courses and gender on mental health of the students. A two way ANOVA was conducted to find the interaction effect of educational courses and gender upon mental health of post graduate students studying in Kolkata. Results indicated a significant interaction effect of educational courses and gender upon mental health of the students group.

\section{INTRODUCTION}

The science of positive psychology operates on three different levels- the subjective level (that includes, emotional well-being, psychological well-being and social well-being), individual level and the group level. The subjective level includes the study of positive experiences such as joy, wellbeing, satisfaction, contentment, happiness, optimism, and flow. This level is about feeling good rather than doing good or being a good person. At the next level , the aim is to identify the constitutions of the 'good life' and the personal qualities that are necessary for being a 'good person', through studying human strengths and virtues, future-mindedness , capacity for love, courage , perseverance , forgiveness, originality, wisdom, interpersonal skills and giftedness.

Mental health is the level of psychological well-being or an absence of mental illness. It is the state of someone who is "functioning at a satisfactory level of emotional and behavioural adjustment". According to the World Health Organization (WHO), mental health includes "subjective wellbeing, perceived self-efficacy, autonomy, competence, intergenerational dependence, and self-actualization of one's intellectual and emotional potential, among others."

Over the past decade, the demographics of the student population have undergone many changes that are of relevance to the provision of mental healthcare. The numbers of young people in higher education have expanded and they have become more socially and culturally diverse. There have been increasing numbers of students drawn from backgrounds with historically low rates of participation in higher education and growing numbers of international students. Social changes such as the withdrawal of financial support, higher rates of family breakdown and, more recently, economic recession are all having an impact on the wellbeing of students and other young people.

Research shows that socially constructed differences between women and men in roles and responsibilities, status and power, interact with biological differences between the sexes to contribute to differences in the nature of mental health problems suffered, health seeking behaviour of those affected and responses of the health sector and society as a whole. However, it is important to remember, when re viewing available evidence in this regard, that there are major gaps. More is known about differences between males and females in some mental health problems such as depression and schizophrenia than others; about adult men and women than about ad o les cents and children; and about the situation in industrialised countries than in the developing world.

Finally the term gender is often used to classify the person as either male or female. In social science however, the concept of gender means much more than biological sex. Gender determines the differential power and control men and women have in their lives. Gender depending on their sexual classification refers to socially constructed expectation regarding the ways in which one is expected to think and behave. These stereotypical expectation regarding are commonly referred to as gender roles, which could make them susceptible, exposed and lead to specific mental health risks.

\section{OBJECTIVES}

a) To find out whether educational courses has a significant impact on mental health.

b) To find out whether gender has a significant impact on mental health.

c) To find out whether there is a significant interaction effect of educational courses and gender on mental health of college students.

\section{METHOD \\ SAMPLE:}

Sample of the present study consisted of 150 males and 150 females semester I Management Students (MBA) from different Management institute recognized as West Bengal Institute and Technology /All India Council for Technical Education/Maulana Abul Kalam Azad University approved colleges (Future Institute of Engineering and Management and UEM (University of Engineering and Management) and 150 males and 150 females semester I General stream Masters' level students from Calcutta University studying in different campuses of Kolkata was considered as participant 
in the present study. The age of the participants vary from $21-$ 25 years.

\section{TOOLS}

\section{A CUSTOIM -BUILT GENERAL INFORMATION SCHE DULE:}

on some specific questions of social demographic status of the subjects including name, gender, age, address, contact information, family type, parents occupation, family income, number of offspring, name of the institution.

The Mental Health Continuum (Long Form): From Languishing to Flourishing in Life (Corey L.M.Keyes, 2008)- The Mental Health Continuum-Short Form (Keyes, 2008 ) is a brief version of its long counterpart, and it is based on the components of Mental Health that can be found in the definition of the concept through the World Health Organization (2005), emotional, social, and psychological wellbeing (Salama-Younes, 2011The items described above had to be scored on a 6-point Likert scale, indicating the frequency of those feelings or situations during the last month. The Likert-scale ranges 14 from never $(=0)$ to every day (=5), with once or twice (=1), about once a week (=2), about 2-3 times a week (=3), and almost every day (=4) in the middle (Westerhof, 2011).

\section{PROCEDURE}

\section{PHASE I:}

The data collection was done by approaching the coordinator of the colleges and the Head of the Department to get the permission from the Dean or Principal for data collection. The study was explained briefly.

\section{PHASE II:}

A sampling frame of 150 male and 150 female management students and 150 male and 150 female general stream masters' level students were developed by scanning relevant attendance registers. The sampling units were selected with the help of a random number table. Data were collected by administering the questionnaires in a compact booklet form to a group of 60 individuals -30 male and 30 female in each group (after explaining the purpose of the study) and assuring their willingness to participate in the study at a time until the required number was reached (Singh,1997).The students were requested to tick the options which suit them or rate each statement as per the instruction given on the respective questionnaire.

\section{PHASE III:}

Data were collected and properly scrutinized. Scoring was done with the help of scoring key. Tabulation was done for each group separately. A factorial analysis of variance of educational courses and gender based on mental health of post graduate students was used.

\section{RESULTS AND DISCUSSION}

Following three hypotheses were developed to test the impact of educational courses and gender on Mental Health of post graduate students studying in Kolkata

\section{HYPOTHESIS I A:}

Mental health varies according to the different educational course of the students.

\section{HYPOTHESIS I B :}

Mental health varies according to the gender of the students

\section{HYPOTHESIS I C:}

There is an impact of interaction between different educational courses and gender on mental health of the students.
ANALYSIS OF THE EDUCATIONAL COURSES AND GENDER AS OBTAINED FROM TWO-WAY ANOVA : Table - 1.1: DESCRIPTIVE STATISTICS FROM TWO -WAY ANOVA

\begin{tabular}{|l|l|l|l|c|}
\hline \multicolumn{5}{|c|}{ Descriptive Statistics } \\
\hline \multicolumn{4}{|l|}{ Dependent Variable: Mental Health } \\
\hline $\begin{array}{l}\text { Educational } \\
\text { courses }\end{array}$ & Gender & Mean & Std. Deviation & $\mathrm{N}$ \\
\hline Management & Male & 161.5533 & 48.09618 & 150 \\
\cline { 2 - 5 } & Female & 168.1933 & 30.43481 & 150 \\
\cline { 2 - 5 } & Total & 164.8733 & 40.31627 & 300 \\
\hline \multirow{2}{*}{$\begin{array}{l}\text { General } \\
\text { Stream }\end{array}$} & Masters' Level & 162.9600 & 19.28656 & 150 \\
\cline { 2 - 5 } & Female & 130.1667 & 41.74265 & 150 \\
\cline { 2 - 5 } Total & Total & 146.5633 & 36.37890 & 300 \\
\cline { 2 - 5 } & Fale & 162.2567 & 36.58706 & 300 \\
\cline { 2 - 5 } & Total & 149.1800 & 41.14142 & 300 \\
\hline
\end{tabular}

Table 1.2: Factorial Analysis of variance of gender based on mental health of different educational courses.

Tests of Between-Subjects Effects

\begin{tabular}{|c|c|c|c|c|c|}
\hline \multicolumn{6}{|c|}{ Dependent Variable: mental health } \\
\hline Source & $\begin{array}{c}\text { Type III Sum } \\
\text { of Squares }\end{array}$ & $\mathrm{df}$ & Mean Square & $F$ & $\mathrm{Sig}$ \\
\hline $\begin{array}{l}\text { Corrected } \\
\text { Model }\end{array}$ & 134250.338 & 3 & 44750.113 & 33.433 & .00 \\
\hline Intercept & 14548919.602 & 1 & 14548919.602 & 10869.692 & .00 \\
\hline $\begin{array}{l}\text { Educational } \\
\text { courses } \\
\text { (Factor A) }\end{array}$ & 50288.415 & 1 & 50288.415 & $37.571 * *$ & .00 \\
\hline $\begin{array}{l}\text { Gender } \\
\text { (Factor B) }\end{array}$ & 25649.882 & 1 & 25649.882 & $19.163 * *$ & .00 \\
\hline $\begin{array}{l}\text { Educational } \\
\text { courses * } \\
\text { Gender }(A * B)\end{array}$ & 58312.042 & 1 & 58312.042 & $43.566 * *$ & .00 \\
\hline Error & 797737.060 & 596 & 1338.485 & & \\
\hline Total & 15480907.000 & 600 & & & \\
\hline $\begin{array}{l}\text { Corrected } \\
\text { Total }\end{array}$ & 931987.398 & 599 & & & \\
\hline
\end{tabular}

The entire analysis was done in SPSS 20 .Again, the research findings might ensure that the F-ratio in respect of Factor $A$ is 37.57 ( $p$-value-0.00) indicates that educational courses (i.e, Management studies and general stream masters' level studies) differ significantly in respect of their mental health condition. . Therefore, the present researcher could accept the research hypothesis i.e. Hypothesis la with strong confidence, inferring that 'Mental health varies according to the different educational course of the students group'.

This research results showed that the mean score of Manag ement courses (164.87) fared better than the mean score of General stream masters' level courses (146.56) in respect of their mental health conditions. The result was inclined to management students that might be due to the fact that management students might are more career oriented while undergoing this course of management, they need be critical in order to implement improvements, they have to do overwork - taking on more tasks than they can handle, and not wanting to delegate than general stream masters' level students. This might helps the management students to promote mental wellness which generally is viewed as a positive attribute leading to better subjective well-being of these students group. This research might examined that for management studies, students might deal with daily activities which enhances mental functioning successfully result in productive activities, fulfilling relationships with other people and the ability to change and to cope with challenging situations. This might be reflected in the a positive functioning in life - that can enhances psychological , emotional and social well-being of these students studying management 
than those undergoing general stream masters' level courses.

Further, the research results might ensure that the F-ratio in respect of Factor B is (19.16) (p-value -0.00) indicates that gender differ significantly in respect of their mental health condition. Therefore, the present researcher could accept the research hypothesis i.e. Hypothesis $1 \mathbf{b}$ with strong confidence, inferring that 'Mental health varies according to the gender of the students'. To put it simply, male and female students would differ significantly in terms of their subjective well-being or positive functioning in life. Previous literature had offered some results in this regards. For example, a significant number of studies had suggested that women were more prone to mental health problems as they might not develop a proper functioning with most parts of themselves, might not have warm and trusting relationships, might not see themselves developing into better people, or do not have a direction in life and are unable to shape their environments to satisfy their needs as because they might experiences aggression towards the self, which stemmed from developmental issues (Rosenfield, Sarah, 1999).

Lastly ,Table 1.2 also pointed out that , the combined effect of educational courses and gender created a significant impact on Mental Health(43.56) ( $p$-value-0.00).Thus Hypothesis lc was accepted and it might be said that "There is an impact of interaction between different educational courses and gender on mental health of the students'.On further inspection of the mean scores (vide Table 1.1) it was found that female management students (168.19) fared better than male management students(161.55) upon their mental health. This might ascertain that female management students might have a positive feeling and positive functioning in life and might focus on mental health promotion. Female students might know how to manage them in order to reach their maximum potential in all aspects of life. Good emotional health might leads to better physical health, prevents diseases, and makes it possible to enjoy life and be happier. The emotional well-being for females might describe that the individuals were in good spirit, they were not hopeless and perceive satisfaction in life. Also, for female management students they might enhances psychological well-being by achieving a state of balance affected by both challenging and rewarding life events. Psychological well-being consists of positive relationships with others, personal mastery, autonomy, a feeling of purpose and meaning in life, and personal growth and development (Keyes and Ryffs, 1999). Apart from this, it was also found that social well-being of female management students improved as the extent to which they might feel a sense of belonging and social inclusion. Participating in various cultural activities within community is not only good for their mental health but can also improve life satisfaction and happiness than male management students.

\section{CONCLUSION}

The findings provide us a better understanding of educational course (i.e management students and general stream masters' level students and gender (male and female) that have the some significant differences upon the mental health. The traditional attitude and beliefs that gender and educational course does not showed any significant differences upon mental health, but considering the social scenario mental health have an important role in connection with the educational course and gender of the student group.

\section{REFERENCES}

1. Broota,K.D.,(2003). Experimental Design in Experimental Research,(Edn) New Age International (P) Limited.

2. Campbell,J.D.,Krueger,K.I.\& Vohs,K.D.(2003). ? Psychological Science(4th Edn) Does high self esteem causes better performance, interpersonal success, happiness or healthier lifestyles,Doi:10.1111/1529-1006.01431.

3. Crocker,J.,\& Park, L.E (2004). Psychological Bulletin (pp392-414) ,The costly pursuit of Self-Esteem.

4. D'Amato,M.R.(1970).Experimental Psychology:Methodology,(2ndEdn). Psychophysics and Learning. New YorkMcGraw Hill,

5. Garrett, H. E. \& Woodwoth, R. S. (1958). Statistics in Psychology and 46
Education(6rd Edn): Descriptive statistics , Analysis of Variance.Paragon International Publishers

6. Guilford ,J.P (1967) Psychometric Methods.Tata Mc.Graw Hill Publishing Co.Ltd;New Delhi

7. Keyes,C.L.M (2002). .Journal of Health and Social Behaviour,43,207-222.The Mental Health Continuum:From languishing to flourishing in life.

8. WHO (2002) Gender and Mental Health, http;//www.who.int/entity/gender /other_heealth/en/genderMH.pdf 